\title{
Marcas do parto: As consequências psicológicas da violência obstétrica
}

\section{Childbirth marks: the psychological consequences of obstetric violence}

\author{
Sabrina Lobato Dias ${ }^{1 *}$, Adriana Oliveira Pacheco \\ 1 Graduanda em Psicologia, Faculdade Estácio de Macapá. Macapá-AP Brasil. E-mail: psi.sabrinadias@gmail.com *Autor para \\ correspondência \\ 2 Psicóloga, Mestre em Psicologia da Saúde pela UMESP/SP, Docente do curso do curso de Psicologia da Faculdade Estácio de Macapá - \\ SEAMA. Macapá-AP Brasil.E-mail: adrianaoliveira1975@bol.com.br
}

Palavras-chave
Violência obstétrica
Parto e trauma
Violência e consequências
psicológicas

\section{Keywords}

Obstetric violence Childbirth and trauma Violence and psychological consequences

\begin{abstract}
A Violência Obstétrica pode ser definida como práticas contra a saúde sexual e reprodutiva da mulher grávida, podendo ainda considerar-se uma apropriação do corpo da mulher, marcado por um tratamento desumanizado. Suas principais tipificações são: violência física, psicológica e sexual. Por exemplo, pode-se citar, respectivamente: a manobra de Kristeller e uso rotineiro de ocitocina; omissão de informações e humilhações; episiotomia e exames de toques invasivos, constantes ou agressivos. Foi constatado no Brasil em 2010 que uma em cada quatro mulheres sofre algum tipo de violência obstétrica. Diante disso, a mulher em paralelo, vivencia um importante momento da sua vida, marcado por transformações físicas, psíquicas e sociais, podendo qualquer evento externo ter impacto significativo na saúde mental da mãe como do bebê. Portanto, a pesquisa teve como objetivo geral identificar as consequências psicológicas que acometem as mulheres vítimas da violência obstétrica. Assim como, analisar quais são esses efeitos e sua relação com a violência de gênero. Para isso, o trabalho teve como percurso metodológico a pesquisa bibliográfica de cunho qualitativo e exploratório. Diante das palavras chaves selecionadas e os critérios de inclusão e exclusão, resultou-se em 10 artigos científicos para a análise de dados, evidenciando-se que a saúde psicológica da mulher é afetada por se tratar de um período de grande vulnerabilidade, havendo a presença de sofrimento emocional, como tristeza, angústia, culpa, medo, inferioridade e insegurança, assim como o aparecimento de comorbidades, traumas e o impacto negativo na sua qualidade de vida. Visando o alcance do objetivo, buscou-se discutir a temática para dar visibilidade, promover a conscientização e estimular a prevenção dessa violência que faz parte da realidade brasileira, assim como contribuir para o meio científico que contém escassez de materiais em relação aos fenômenos psicológicos.
\end{abstract}

The obstetric violence can be defined as practices against the sexual and reproductive health of pregnant woman, and it may also be considered an appropiation of the woman's body, made by dehumanized treatment. Its main types are: physical violence, psychological and sexual violence. For example, one can quote: The Kristeller maneuver and routine use of ocytocin; omission of informations and humiliation; episiotomy and invasive, constant or aggressive pelvic examination. It was noted in Brazil in 2010 that one in every four woman suffer some kind of obstetric violence. In view of this, the woman experiences an important moment in her life, marked by physical, psychic and social transformations, and any external event could have a significant impact on health mother's mental as well as the baby's health. Therefore, the general goals of the research was to identify the psychological consequences that affecting women victms of obstetric violence. As well as to analyse what these effects are and their relation to the gender violence. For that, the work had as methodological route the bibliographical research of qualitative nature. Given the selected keywords and the inclusion and exclusion criteria resulted in 10 scientific articles for data analisys, showing that the psychological health of woman is affected because it is a period of big vulnerability, with the presence of emotional distress, such as sadness, anguish, fear, inferiority and insecurity, as well as the appearance of comorbidities, trauma and negative impact on her quality of life. Aiming at the reach of objective, it was looked to discuss the theme to give visibility, raise awareness and encourage the prevention of this violence that is part of the brazlian reality, as well as to contribute to scientific environment that is scarce in materials regarding the psychological phenoma.

\section{INTRODUÇÃO}

No final do século XIX as transformações na área da obstetrícia médica refletiram diretamente nas tradições dos partos naturais. Antes, o parto era realizado por parteiras nas casas de familiares das mulheres, com base na dinâmica fisiológica e natural de cada uma. Com as mudanças, o modelo tecnocrático buscou o controle desse evento, guiado, principalmente, pelo princípio de risco ou de patologia que o parto poderia oferecer à mãe e ao bebê. Desde então, o parto começou a ser mais medicalizado e intervencionista, sendo este modelo, muitas vezes, acompanhado de dor e sofrimento 
(ZANARDO et al., 2017). As seguintes frases: "Na hora que você estava fazendo, você não tava gritando desse jeito, né? ", "Se você continuar com essa frescura, eu não vou te atender", "Na hora de fazer você gostou, né?" São alguns exemplos de relatos que fazem parte da realidade do atendimento obstétrico à mulher. Portanto, segundo a pesquisa da Fundação Perseu Abramo em 2010, uma em cada quatro mulheres sofreu algum tipo de Violência Obstétrica (V.O) no Brasil (BRASIL, 2012, p.2).

Assim, pode-se caracterizar como V.O às práticas contra a saúde sexual e reprodutiva da mulher, podendo ser cometida por profissionais que atuam no ambiente da saúde. Refere-se a apropriação do corpo e dos seus processos reprodutivos, realizado por profissionais que exercem um tratamento desumanizado, medicalizado e patológico diante dos processos naturais do corpo da mulher. Os tipos de V.O podem ser caracterizados em caráter físico, psicológico, sexual, institucional, material e midiático (BRASIL, 2012; PEREIRA et al., 2016).

A partir dos levantamentos históricos descritos na literatura e considerados neste estudo, pôde-se perceber que a V.O advém de uma violência contra mulher e que se refere a questões de gênero. Isso significa que a construção social e simbólica de uma mulher, está quase sempre associada à uma dominação masculina, pois, as relações de poder que se estabeleceram entre ambos, constituem uma relação desigual e de inferiorização. No contexto médico e obstétrico, essa relação se repete. $O$ seu corpo se torna objeto controlado pela prática médica (SANTOS; IZUMINO, 2005; QUEIROZ et al., 2017; AGUIAR, 2010).

Para a Psicologia, a violência contra a mulher, independente do seu tipo, causa comprometimentos à saúde física, mas o que se enfatiza são as consequências que vão além desses danos imediatos. Pois, o trauma reflete seriamente na saúde mental da mulher, principalmente vivenciado em um momento de parto ou/e pós-parto, considerado psicologicamente, como turbulento e vulnerável para a gestante e o bebê (CFP, 2013; MUNIZ; BARBOSA, 2012; SOUSA, 2008). Dessa forma, a pesquisa foi motivada pelos significativos dados estatísticos que apontam essa realidade, assim como vivência pessoal do tema, soma-se a isso a percepção da escassez de materiais na literatura que analisam os impactos psicológicos dessa violência na vida da mulher. Por isso, o artigo tem sua relevância por analisar esse fenômeno com uma abordagem psicológica, para conhecimento público e profissional do quanto o cuidado com esse momento precisa ser reconhecido e respeitado, justamente por se tratar de um aspecto de saúde biopsicossocial.

Em suma, o estudo partiu da seguinte problematização: Quais as consequências psicológicas da V.O para a mulher? Buscou-se responder essa problemática a partir da técnica de pesquisa bibliográfica de cunho qualitativo, com o intuito de investigação exploratória, através de artigos científicos, dissertações, teses, livros e sites, considerando, além dos dados, o percurso histórico realizado por essas fontes, com o intuito de entender o fenômeno da V. O., inclusive, nos aspectos culturais.

Assim, o objetivo da pesquisa foi identificar as consequências psicológicas que acometem as mulheres vítimas da V.O; analisar, através dos relatos de experiências contidos na literatura, como as mulheres submetidas à V.O perceberam o fenômeno; ademais, buscou-se destacar o que a literatura contribui em relação a violência de gênero e o fenômeno estudado. Finalmente, pretendeu-se discutir a atuação do psicólogo diante do tema em questão, já que é um campo mais ocupado pela enfermagem e medicina. Espera-se que esta pesquisa possa sensibilizar e trazer informações para profissionais da saúde e psicólogos, com o intuito de que, com o conhecimento, possa-se combater um fenômeno muitas vezes escondido no campo hospitalar, mas que acarreta prejuízos significativos à saúde mental de inúmeras mulheres no Brasil.

\section{MÉTODOS}

É essencial destacar os procedimentos metodológicos que a pesquisa foi submetida para a coleta de dados, resultados e discussão. Logo, trata-se de uma revisão bibliográfica integrativa, de estudo exploratório e de abordagem qualitativa, que se propôs a analisar os relatos de experiência de mulheres vítimas de V.O e identificar as consequências psicológicas sofridas. É válido ressaltar que a pesquisa qualitativa, considera aspectos da realidade vivenciada pelos sujeitos, como a dinâmica das relações sociais, que não podem ser quantificadas (GIL, 2017; GERHARDT; SILVEIRA; 2009).

Assim, o estudo foi realizado a partir de sites, artigos científicos, teses e dissertações publicados em plataformas científicas, sendo estas: Google Scholar (Google acadêmico), Biblioteca Virtual em Saúde (BVS) e The Scientific Electronic Library Online (SciELO). Para tanto, a investigação se deu com base nos seguintes descritores: "Violência Obstétrica", "Parto e Trauma" e "Violência e Consequências Psicológicas".

Fizeram parte da pesquisa os trabalhos que discutiam sobre V.O, no período de 2010 a 2019, considerando que no ano de 2010, foram realizadas duas pesquisas que conseguiram levantar dados nacionais referentes ao tema, destacando-se por sua relevância e contribuindo para uma consolidação científica (SENA; TESSER, 2017). Utilizou-se como critérios de exclusão as obras que não eram de língua 
portuguesa e não correspondiam aos objetivos da pesquisa.

Dessa forma, acessou-se as plataformas Scielo, BVS e Google acadêmico, com os descritores selecionados, e foram encontrados, respectivamente, 24, 38 e 8.200 produções científicas em cada plataforma. Os artigos das plataformas Scielo e BVS foram separados e os resumos lidos na íntegra, para a seleção dos trabalhos, conforme critérios de inclusão e exclusão. Em relação ao Google acadêmico, percebeu-se que muitos dos trabalhos não correspondiam ao tema e que algumas obras estavam reproduzidas nas plataformas Scielo e BVS. Contudo, é importante demarcar que desde o início da pesquisa se percebeu, apesar do quantitativo apresentado nas buscas, a dificuldade de encontrar materiais que correspondessem aos objetivos e aos critérios de inclusão. A escassez evidenciada motivou ainda mais as autoras para a confecção da obra.

O período de coleta de dados ocorreu entre março e novembro de 2019, período em que foram realizadas leituras prévias dos resumos e selecionados materiais que estavam de acordo com o critério de inclusão e exclusão. Após esse processo, os textos foram lidos na íntegra e os elementos foram analisados de forma qualitativa, o que possibilitou uma inferência do significado e processo dos dados. Assim, tratouse os materiais em categorias correspondentes à "violência obstétrica", "violência de gênero" e "consequências psicológicas" para uma melhor organização da pesquisa.

\section{RESULTADOS E DISCUSSÃO}

Apoiada à metodologia exposta, a plataforma de pesquisa que mais correspondeu a demanda dos objetivos foi o Google acadêmico, por envolver um maior alcance de artigos de acordo com a proposta, pois, houve escassez de materiais pesquisados nas outras plataformas com os descritores escolhidos, apresentando dificuldade para condizer ao intuito da pesquisa. Vale salientar que não foi possível a leitura da totalidade encontrada na plataforma, mas 90 produções científicas foram acessadas e realizadas leituras exploratórias. A partir dos critérios aplicados, obteve-se como resultado 10 artigos em concordância ao objetivo geral, discriminados na Quadro 1.

\section{V.O e as implicâncias nos aspectos psicológicas do mulher}

O campo da Psicologia Pré e Perinatal ressalta o evento de dar à luz como "decisivo em vários aspectos da vida e na saúde física e mental tanto do bebê como da mãe" (MUNIZ; BARBOSA, 2012, p. 9). Sabe-se que o parto traz grandes alterações físicas, hormonais, psíquicas, e por outro lado, a mulher se vê diante de uma transformação dos seus papéis sociais e suas relações interpessoais. Portanto, a Psicologia identifica esse evento como turbulento, justamente por transformações tão importantes e pelo impacto causado no ciclo das suas relações. Isso demonstra que além dos processos físicos de saúde, existem agentes essenciais envolvidos no ciclo de gravidez da mulher referente a sua saúde mental. Por consequência, existem possibilidades do aparecimento de um quadro de tristeza ou até de episódios psicóticos, podendo considerar o pós-parto uma fase que aumenta a probabilidade do surgimento de transtornos psiquiátricos, e quando acontece, resulta na interferência de um vínculo afetivo saudável entre a mãe e bebê (MUNIZ; BARBOSA, 2012).

A partir desse ponto de vista, pode-se entender em como esse período trata-se, por si só, de transformações biopsicossociais, o que instiga a reflexão desse processo pode ser, ou não, mais intenso quando vivido por uma violência. Dessa forma, foi possível alcançar o objetivo da pesquisa através dos trabalhos contidos na literatura que possuem relatos de experiência e as consequências psicológicas que podem acarretar à mulher vítima de V.O. Assim, como já mencionado, a gestação é uma fase marcada por fragilidades emocionais, levando-se em conta a V.O sofrida, o estado psíquico da mulher torna-se vulnerável a não suportar tanta pressão, o que pode ocasionar o aparecimento de transtornos psicológicos. Pois, além de suas transformações biopsicossociais, é um período que exige readaptação a sua nova vida, dando vulnerabilidade mental para o surgimento intenso de angústia e medo, sendo o aspecto emocional instável e o desconforto físico dois fatores que seguem juntos desde a gestação (SILVA; SILVA; ARAÚJO, 2017)

Portanto, esses sentimentos aparecem como consequência da V.O, sendo o constrangimento o primeiro sentimento que as mulheres enfrentam, seguido de violência psicológica por agressões verbais. Além disso, a angústia é intensificada, desenvolvendo a sensação de inferioridade, medo e insegurança, através da humilhação presente nas práticas dos profissionais de saúde, que "criam ou reforçam sentimentos de incapacidade, inadequação e impotência da mulher e do seu corpo" (SILVA; SILVA; ARAÚJO, 2017, p. 32).

No estudo de Silva, Silva e Araújo (2017) as consequências psicológicas ficaram claras nos relatos coletados através de entrevistas com 20 mulheres vítimas de V.O, de variadas idades, residentes na cidade de Alagoa Grande - PB, ao exporem, em sua maioria, sentimento de revolta, tristeza e medo. Com essas análises, percebe-se que os sofrimentos advindos da violência sofrida na gestação e no trabalho de parto, perpassam por prejuízos psíquicos que podem se 
Quadro 1. Tabulação dos artigos utilizados para a produção do trabalho.

\begin{tabular}{|c|c|c|c|}
\hline $\begin{array}{l}\text { Nome dos } \\
\text { Autores }\end{array}$ & Ano & Título & Plataforma \\
\hline AGUIAR, J.M. & 2010 & $\begin{array}{l}\text { Violência institucional em maternidades } \\
\text { públicas: hostilidades ao invés de acolhimento } \\
\text { como uma questão de gênero. }\end{array}$ & Scielo \\
\hline $\begin{array}{c}\text { MUNIZ, B.; } \\
\text { BARBOSA, R. }\end{array}$ & 2012 & $\begin{array}{l}\text { Problematizando o atendimento ao parto: } \\
\text { cuidado ou violência? }\end{array}$ & $\begin{array}{l}\text { Google } \\
\text { acadêmico }\end{array}$ \\
\hline $\begin{array}{l}\text { CONSELHO } \\
\text { FEDERAL DE } \\
\text { PSICOLOGIA }\end{array}$ & 2013 & $\begin{array}{l}\text { Referências técnicas para atuação de } \\
\text { psicólogas (os) em programas de atenção à } \\
\text { mulher em situação de violência. }\end{array}$ & $\begin{array}{l}\text { Google } \\
\text { acadêmico }\end{array}$ \\
\hline LANGE, M. & 2015 & $\begin{array}{l}\text { Outras dores além do parto: um estudo de caso } \\
\text { com mulheres vítimas da violência obstétrica. }\end{array}$ & $\begin{array}{l}\text { Google } \\
\text { acadêmico }\end{array}$ \\
\hline $\begin{array}{l}\text { BARBOZA, } \\
\text { L.; MOTA, A. }\end{array}$ & 2016 & $\begin{array}{l}\text { Violência obstétrica: vivências de sofrimento } \\
\text { entre gestantes o Brasil. }\end{array}$ & $\begin{array}{l}\text { Google } \\
\text { acadêmico }\end{array}$ \\
\hline $\begin{array}{l}\text { PORTELA, A.; } \\
\text { SILVA, E. A. }\end{array}$ & 2017 & $\begin{array}{l}\text { A psicologia dialogando com a violência } \\
\text { obstétrica e o direito da mulher: uma revisão } \\
\text { bibliográfica. }\end{array}$ & $\begin{array}{l}\text { Google } \\
\text { acadêmico }\end{array}$ \\
\hline $\begin{array}{l}\text { QUEIROZ, T. } \\
\quad \text { et al. }\end{array}$ & 2017 & $\begin{array}{l}\text { Violência obstétrica e suas perspectivas na } \\
\text { relação de gênero. }\end{array}$ & $\begin{array}{l}\text { Google } \\
\text { acadêmico }\end{array}$ \\
\hline RIBEIRO, P. & 2017 & $\begin{array}{l}\text { Significados da maternidade para mulheres } \\
\text { que vivenciaram a violência obstétrica. }\end{array}$ & $\begin{array}{l}\text { Google } \\
\text { acadêmico }\end{array}$ \\
\hline $\begin{array}{l}\text { SILVA, F.; } \\
\text { SILVA, M.; } \\
\text { ARAÚJO, F. }\end{array}$ & 2017 & $\begin{array}{l}\text { Sentimentos causados pela violência obstétrica } \\
\text { em mulheres de município do Nordeste } \\
\text { Brasileiro. }\end{array}$ & $\begin{array}{l}\text { Google } \\
\text { acadêmico }\end{array}$ \\
\hline $\begin{array}{l}\text { ROCHA, M.; } \\
\text { GRISI, E. }\end{array}$ & 2017 & $\begin{array}{l}\text { Violência obstétrica e suas influências na vida } \\
\text { de mulheres que vivenciaram essa realidade. }\end{array}$ & $\begin{array}{l}\text { Google } \\
\text { acadêmico }\end{array}$ \\
\hline
\end{tabular}

tornar duradouros, ocasionando traumas que refletem nas mulheres como o medo de uma nova gestação, por terem experienciado de forma negativa a anterior.

Na pesquisa de Rocha e Grisi (2017) com 7 puérperas do município de Vitória - Bahia, também foi constatado, por meio de entrevista gravada, seguida de um roteiro estruturado, que a V.O é um tipo violência psicológica que ocasiona traumas nas mulheres e acabam desenvolvendo a depressão pós-parto. Outras consequências confirmadas foram em relação a sexualidade da vítima após o procedimento de episiotomia, sendo a sua vida sexual e autoestima afetadas, interferindo na sua imagem corporal e despertando incômodos físicos, como a dor.

Rocha e Grisi (2017) analisaram em seus estudos a relação do parto e de transtornos psicológicos em mulheres, e destacaram que dentro do grupo de mulheres que tiveram um parto traumático, $60 \%$ apresentaram sinais de estados depressivos no início do seu pós-parto, logo, o “[...] potencial 
para causar benefícios ou danos psicológicos está, dessa forma, presente em cada parto" (MUNIZ; BARBOSA, 2012, p. 8). Portanto, é possível perceber que sintomas depressivos rodeiam o processo da gravidez e conseguem ser intensificados quando esse desenvolvimento é afetado negativamente. As pesquisas evidenciam que nesse período são necessários atenção e zelo para que as consequências não sejam tão prejudiciais, contando que o próprio pós-parto já se encarrega da necessidade de tantas (re) adaptações.

Vale ressaltar que quando esse momento é bem respeitado e a mulher se sente mais informada, isso contribui para a diminuição da sua dor e cria um processo mais positivo. Pois, dessa forma, sua segurança e confiança são alimentadas para que consiga ter concentração no seu objetivo de conseguir dar à luz. Caso contrário, a falta de informação e humanização produz mais ansiedade, ocasionando na experiência uma sensação mais dolorosa e insegura (ROCHA; GRISI, 2017).

Toda atividade natural em torno da gravidez é esperada pela mulher, porém, quando acontece alguma situação de violência no seu processo, principalmente por quem exerce o papel de cuidador e proteção - no caso, os profissionais da saúde - resulta em um impacto significativo no funcionamento do seu psicológico e comportamento (RIBEIRO, 2017). Nesse caso, pode-se imaginar como as expectativas criadas para esse momento são quebradas, gerando sentimento de decepção e perda simbólica pelo o que se planejou. Mesmo sabendo que tudo o que fora planejamento para o parto é incerto, a violência não costuma ser desejada pelas pessoas, principalmente quando se trata de um ambiente que significa cuidado/ajuda, como se espera de um hospital.

Os desenlaces das vivências experimentadas durante esses momentos fazem parte da interpretação singular de cada pessoa e os seus significados envolvem "os sentimentos, os pensamentos e as relações das mulheres no processo de construção dos significados da maternidade após uma experiência de violência obstétrica" (RIBEIRO, p. 30, 2017). Ainda é preciso considerar o impacto que se pode ter no fazer da maternidade de cada mulher, isso significa que as consequências de uma violência têm grandes possibilidades de atravessarem o sentido de ser mãe para quem "pagou caro" por ter seu filho no colo. E aqui não se refere ao sentido literal da expressão, mas sim, às marcas significativas que acarretam à história dessa mulher.

Nas pesquisas dos autores citados acima, também foi possível perceber sentimentos positivos gerados nas mulheres que sofreram V.O, sendo um deles o sentimento de gratidão vivenciado por elas após verem seus bebês nascidos, saudáveis, o que acabava gerando um conforto ao perceberem que, apesar de toda situação presenciada, os seus filhos estavam seguros em meio a tamanha tensão.

No trabalho de campo de Lange (2015), que envolveu 5 mulheres de 25 a 35 anos, por meio de entrevistas, detectouse suas percepções sobre a V.O. Nesse estudo, foi percebido, através das falas transcritas das participantes, que o estresse, medo, indignação, constrangimento e desvalorização foram os fenômenos psicológicos identificados como consequências da V.O. Com base nesses dados, pode-se entender o que a ciência psicológica esclarece sobre os processos psíquicos referentes à violência contra mulher:

Com frequência, alterações psíquicas na mulher podem surgir em função do trauma, entre elas o estado de choque que ocorre imediatamente após a agressão, permanecendo por várias horas ou dias. Entretanto, independentemente do tipo de violência e o comprometimento causado à saúde física, as sequelas geralmente vão além dos danos imediatos. $O$ aspecto traumático da violência pode comprometer seriamente a saúde mental da mulher, especialmente porque interfere em sua autonomia, gerando sentimentos duradouros de incapacidade e de perda da valorização de si mesma (CFP, 2013, p. 71).

Assim, é compreensível que o trauma se instale independentemente do tipo de violência sofrida, podendo variar em durabilidade e consequências. Mas o importante a destacar é a mensuração dos danos que vão além dos que aparecem de forma instantânea, que se referem aos efeitos contínuos, que tem impacto significativo em como a mulher se vê, se sente e se põe diante do seu mundo.

No trabalho de Lange (2015) foi evidenciado em uma das entrevistadas a consequência psicológica a longo prazo, pois, a mesma sofreu V.O a 11 anos antes da coleta de dados da pesquisa, contudo, o autor expôs que foi possível perceber as emoções que mobilizavam a entrevistada, assim como o estresse e o esgotamento emocional, por relembrar o que passou. S1, assim denominada, ao contar o que vivenciou, disse: "Meu Deus! Fico nervosa, como se tivesse passando tudo de novo, que nem contando pra você aqui, vou ficando tensa" (LANGE, 2015, p. 20).

$\mathrm{Na}$ mesma pesquisa, também se identifica o sentimento de medo evidenciado pelas mulheres, e sua causa se relaciona como uma reação que interrompeu o projeto de vida de 2 participantes, justamente por paralisar o desejo futuro de uma nova gestação. É um dado que já foi demonstrado por Silva, Silva e Araújo (2017) neste trabalho, repercutindo como uma das principais consequências da V.O, ou seja: o medo de 
uma próxima gestação.

Ademais, foi possível identificar o sentimento de indignação que se faz presente nas mulheres do mesmo estudo. $\mathrm{O}$ autor salienta:

A revolta sentida por uma situação de injustiça e a incapacidade de se opor a essa situação criou em algumas destas mulheres o sentimento de indignação. $O$ estado de vulnerabilidade em que se encontravam reforçou a dificuldade de se posicionar diante da equipe de assistência e é deste modo que se estabelece uma relação assimétrica entre profissionais e parturientes (LANGE, 2015, p.22).

Nesse sentido, é notada a dificuldade que a mulher tem em responder de maneira imediata à violência sofrida, encontrando barreiras para se defender e permanecendo na posição passiva por se encontrar em um estado totalmente desamparado. Percebe-se então que essa postura adquirida pela mulher, faz com que, posteriormente, surjam os sentimentos de indignação, revolta e de incapacidade por não ter conseguido corresponder a sua vontade de se manifestar diante do abuso. Esse comportamento presente nos casos, resulta na manutenção das ações dos profissionais de saúde, por não surgirem reações, por parte das mulheres, que parem esse tipo de atuação violenta, caracterizando uma relação vertical entre as usuárias do serviço e a equipe de saúde.

A partir de uma relação assimétrica, estabelecida entre a equipe e a usuária, pode-se dar início a ideia de que a violência obstétrica também pode ser uma violência de gênero. Barboza e Mota (2016) referem que o momento do parto é caracterizado por uma expectativa de espera em volta do acolhimento e cuidado para a mãe e bebê, contudo, o que se percebe é uma prática com base no poder e uma assistência de violência sob a mulher, principalmente discriminatória em relação ao gênero, classe e etnia. Desse modo, os autores se referem à violência no parto contra mulher a partir de uma relação desigual, existente entre o feminino e o masculino, principalmente numa perspectiva de dominação do homem, em vários aspectos, sob a mulher.

\section{Relação entre V.O e violência de gênero}

A história da sociedade brasileira ainda traz marcas de relações baseadas no modelo patriarcal - mesmo que com o passar dos anos isso tenha diminuído - o que significa uma visão de homem provedor, que detém a força, o controle, a inteligência e considera a mulher como um ser frágil, com o dever de obedecer, procriar e ser um exemplo de moral e bons costumes. Assim, a relação de poder do homem sobre a mulher, pode-se comparar com a posição que esta ocupa no momento do seu parto, e o papel que o médico exerce sobre a mesma, já que, nesse contexto, a autonomia da mulher também não é respeitada e suas vontades não são consideradas. São ideias que partem das construções sociais e históricas do lugar e papel da mulher perante a sociedade, principalmente em relação à submissão ao sexo masculino e pela forma que essa posição é assumida por ela (PORTELA; SILVA, 2017).

Partindo dessa ideia, da posição de submissão a qual a mulher vive social e historicamente, é que este estudo observou no contexto da saúde que a paciente obstétrica é submetida ao poder de alguém que detém o saber, o conhecimento, e que determina a forma de condução do parto, independentemente do desejo da parturiente.

Nessas relações de poder, percebe-se como a figura médica se enquadra no topo dessa hierarquia social na área da saúde, não apenas por deter uma autoridade pelo o seu conhecimento científico, "mas também em relação à cultura e à moral, dominando muitas vezes a conduta, os valores e as crenças de cada pessoa" (QUEIROZ et al., 2017, p. 68). É possível encontrar na literatura a relação aos maus tratos vividos pelas pacientes com práticas discriminatórias realizadas por profissionais da saúde. A mulher acaba sendo marcada por uma inferioridade, e no contexto institucional, o seu corpo e sua sexualidade se tornam objetos controlados pela prática médica (AGUIAR, 2010).

Os estudos conseguem demonstrar essa relação de poder desigual, principalmente quando a fala das mulheres não é reconhecida, é ignorada no atendimento pré-natal e parto. Dessa forma, o poder de decisão se centraliza nos profissionais - na maioria das vezes, na figura do médico - que escolhe o que deve ou não ser feito num momento que diz respeito totalmente à mulher, reafirmando "a situação de subordinação materializada no controle e vigilância do corpo feminino" (MUNIZ; BARBOSA, 2012, p. 7). Essa relação profissional e parturiente - de interação e de possíveis violências, inicia no momento que as opiniões dos profissionais podem influenciar em todo processo de trabalho de parto da mulher (QUEIROZ et al., 2017).

Contudo, apesar dos esforços de pesquisadores para fazer a sociedade refletir e dar publicidade ao fenômeno da V. O., é válido ressaltar que este é um tema novo no meio científico e jurídico. Pereira et al. (2016) apontam a Argentina, em 2004, como o primeiro país latino americano a reconhecer a V.O; já em 2007, a Venezuela também registra o fato como delito; no entanto, o Brasil não possui uma lei específica que ampare e reconheça a V.O como uma violação dos direitos da mulher. Todavia, há no país documentos elaborados para a promoção de saúde das mulheres grávidas, sendo eles: Ministério da 
Saúde: Parto, Aborto e Puerpério (2001), Humanização do Parto no Brasil (2002) e o dossiê Parirás com Dor (BRASIL, 2012). Estes têm como função mudar a realidade do parto, tornando-o mais humanizado e gerar qualidade de vida no nascimento (LANGE, 2015).

No Brasil, o Ministério da Saúde (MS) publicou uma nova orientação relacionada ao termo "V.O". No dia 3 de maio de 2019 o MS orientou que o termo deveria ser evitado e até retirado dos documentos de políticas públicas, pois, para o governo, o uso se refere a um significado intencional da força violenta contra a mulher na assistência ao parto, o que generaliza a prática médica nesse momento, já que não são em todas as situações que a expressão é aplicada. Para o MS (2019), "tanto o profissional de saúde quanto os de outras áreas, não têm a intencionalidade de prejudicar ou causar dano". Esta foi uma medida motivada pelas entidades médicas que acompanham o parecer publicado pelo Conselho Regional de Medicina (CFM) em 2018, que afirmou que o termo V. O. é uma agressão contra a ciência médica e suas especialidades.

Em contrapartida, o Ministério Público Federal publicou uma recomendação no dia 7 de maio de 2019, com o objetivo de indicar ao MS uma reavaliação para reconhecer e legitimar o uso do termo "V.O". A procuradora da República Ana Carolina Previtalli, responsável pelo documento, afirma que essa postura do MS desconsidera as orientações da Organização Mundial da Saúde, sendo que o termo já é amplamente usado por documentos científicos. Ainda evidencia melhor planejamento de ações voltadas a cessar práticas violentas no parto, ao invés de trabalhar especificamente em abolir o termo. Após a publicação, o MS reconheceu, através de um ofício, a legitimidade da expressão até então discutida, o que considera o direito arbitrário das mulheres de caracterizarem como melhor identificar suas experiências no parto.

Desse modo, observa-se que ainda há lacunas em volta do tema proposto, sem consolidação do seu devido reconhecimento para prevenção e cuidado de feridas simbólicas e físicas.

\section{CONSIDERAÇÕES FINAIS}

A partir dos resultados que a pesquisa proporcionou foi possível evidenciar que há escassez em materiais científicos sobre o tema abordado em relação à psicologia, o que resultou em um número pequeno de amostra. Isso reflete a dificuldade na procura por pesquisas com propriedade nesse conhecimento específico e aprofundado, que abordassem as consequências psicológicas da V.O, já que a maioria dos materiais foram produzidos por outras áreas, como enfermagem, medicina e direito. Encontrou-se, inclusive, termos específicos da psicologia como tema de pesquisa da área de enfermagem, um deles foi a palavra "psicossocial". Porém, não há um desmerecimento das áreas citadas, pois, suas contribuições são ricas e válidas, mas é preciso perceber que a psicologia precisa ocupar espaços necessários na área da saúde, para uma melhor cientificidade ao tema. Em sua maioria, só há a identificação das consequências, mas não há discussão teórica suficiente dos efeitos a curto e longo prazos dessa violência na vida das mulheres.

Entretanto, há uma realidade brasileira preocupante sobre a V.O, pois, foi percebido variados trabalhos com relatos de experiência que retratam a violência vivida por mulheres, em sua maioria nos setores públicos, mas também presente nos setores privados. Mesmo assim, nem todas as vítimas conseguem identificar as formas de V.O, naturalizando uma prática que transgride os direitos humanos das mesmas. É uma violência velada, sustentada por uma relação desigual de gênero, sendo o saber médico considerado referência incontestável em um momento que a subjetividade da mulher é ignorada; é submetida a alguém que culturalmente sabe melhor do que a própria paciente o que ela sente e deseja para si mesma e para seu bebê. O que acaba tornando muitos casos impunes, por se estabelecer uma figura simbólica que detém o conhecimento exato e adota, assim, uma comunicação totalmente vertical.

Lange (2015) em suas pesquisas levantou o questionamento: "a reflexão que se pode fazer se dá no sentido de imaginar que se a própria V.O é considerada invisível, como reconhecer as marcas psicológicas decorrentes desta violência?". Pois, se há dificuldades em identificar as violências físicas desse fenômeno, imagina-se como ainda é desafiante encontrar os efeitos emocionais dele.

A partir da revisão da literatura feita, é evidente que as marcas do parto existem, mas que essas vão além de cicatrizes físicas, são marcas no inconsciente, nas memórias, lembranças, nas emoções, nos momentos revividos individualmente. Muito se fala em um país de futuro juvenil, mas como pensar no futuro de crianças/jovens se no momento do seu nascimento já são muitas vezes marcados por violência e desrespeito? É esquecido que para crianças saudáveis, precisa-se de pais saudáveis, contudo, parturientes traumatizadas pelo fenômeno da V.O apresentam chances de desencadear sequelas emocionais que podem marcar suas vidas e suas relações.

Dessa forma, visualiza-se a necessidade da psicoeducação das mulheres grávidas em relação aos seus direitos, mas como também dos profissionais de saúde com os seus deveres. A psicoeducação refere-se a uma ferramenta que fornece conhecimento de determinado tema, nesse caso, dos direitos, 
e a descoberta dos limites que cada um tem num momento tão singular.

Em relação a psicologia, não há significativa quantidade de materiais específicos na literatura científica em relação a sua atuação frente a V.O Porém, o Conselho Federal de Psicologia criou um documento de Referências técnicas para atuação de psicólogas (os) em Programas de Atenção à Mulher em situação de Violência, já citado no artigo. Então, há respaldo científico em relação a atuação na violência contra mulher em geral. Entretanto, existe uma crescente área da psicologia perinatal que engloba os cuidados às mulheres e ao bebê no período pré, parto e pós-parto, sendo uma possível porta de entrada para uma melhor visualização do problema que se discutiu aqui.

Contudo, foi possível encontrar que a prática psicológica em relação a temática pode envolver o empoderamento materno, acolhimento, ressignificação, reconstituição emocional e ideológica que a mulher se encontra após a ocorrência da V.O, principalmente por ter ficado explícito como trauma o planejamento de outro filho no futuro, processo diretamente ligado a violência vivida no parto anterior. O trabalho com a família e em grupo também é válido diante de tantas transformações no contexto em que vive a mulher. Sem desconsiderar o trabalho preventivo como mudança dessa realidade atual, mesmo com tantas conquistas reconhecidas nesses 20 anos.

Sobre a legislação brasileira, percebe-se que os ministérios não conseguem se entender para unificar ações que possam aperfeiçoar os atendimentos às parturientes, proporcionando-lhes melhores condições de vida e o combate a V.O Portanto, conclui-se a necessidade de mais pesquisas, preferencialmente de campo, para um melhor aprofundamento das consequências psicológicas de um parto violentado, principalmente na cidade de Macapá-AP, por apresentar uma precária assistência pública à mulher grávida, como mostram os veículos de comunicação local.

Devido a isso, no site do Ministério Público do Estado do Amapá é possível acessar informações sobre o assunto, pois, no ano passado (2019), no mês de agosto, o coordenador das Promotorias de Defesa da Saúde do Ministério Público do Amapá e Promotor de Justiça André Araújo teve a iniciativa de propor uma palestra sobre V.O para defensoras e defensores públicos do Estado. O evento foi realizado no auditório do Complexo Cidadão Centro e faz parte da campanha nacional "Em Defesa Delas", com o objetivo de capacitar os defensores sobre o tema proposto. Em uma das suas falas, o Promotor referiu que já pôde presenciar o atendimento desumano, estes acontecendo no chão, e mulheres dividindo o mesmo leito, para complementar, afirmou: "o fato é que as usuárias do Sistema Único de Saúde no Amapá sofrem violência obstétrica diariamente, pois aqui ainda estamos lutando para termos o básico" (ARAÚJO, 2019).

Por fim, em grande maioria, os estados do Brasil no sistema público, compartilham a mesma realidade, portanto, buscou-se contribuir com a discussão do tema abordado por se tratar de uma motivação a mudança em relação ao significado do começo da vida, um momento tão importante quanto a continuação da mesma.

\section{REFERÊNCIAS}

AGUIAR, J. M. Violência institucional em maternidades públicas: hostilidades ao invés de acolhimento como uma questão de gênero. 2010. Tese de Doutorado (Pósgraduação em Medicina Preventiva) - Faculdade de Medicina, Universidade de São Paulo, São Paulo. Disponível em: <http://www.teses.usp.br/teses/disponiveis/5/5137/tde21062010-175305/pt-br.php>. Acesso em: 1 mai. 2019.

BARBOZA, L.; MOTA, A. Violência obstétrica: vivências de sofrimento entre gestantes do Brasil. Revista Psicologia, Diversidade e Saúde. Salvador, v. 5, n.1, p. 119-129, 2016. Disponível em: <https://www5.bahiana.edu.br/index.php/psicologia/arti cle/view/847/598>. Acesso em: 04 nov. 2019.

BRASIL, Ministério Público Federal. Inquérito Civil Recomendação no 29/2019, de 07 de maio de 2019. São Paulo, SP. Disponível em: <http://www.mpf.mp.br/sp/sala-deimprensa/docs/recomendacao_ms_violencia_obstetrica. pdf/>. Acesso em: 31 out. 2019.

BRASIL, Senado Federal. Violência Obstétrica - "Parirás com dor". Dossiê elaborado pela Rede Parto do Princípio para a CPMI da Violência Contra as Mulheres, 2012. Disponível em:

<https://www.senado.gov.br/comissoes/documentos/SS CEPI/DOC\%20VCM\%20367.pdf.>. Acesso em: 3 mai. 2019. CONSELHO FEDERAL DE MEDICINA. Parecer CFM no 32/2018, de 23 de outubro de 2018, Brasília, DF. Disponível em: <http://estaticog1.globo.com/2019/05/07/ParecerCFMVi olenciaObstetrica.pdf>. Acesso em: 06 nov. 2019.

CONSELHO FEDERAL DE PSICOLOGIA, Referências técnicas para atuação de psicólogas (os) em Programas de Atenção à Mulher em situação de violência. 1. Ed. Brasília, 2013. Disponível em:<http://crepop.pol.org.br/5804_referencias-tecnicaspara-atuacao-de-psicologas-os-em-programas-deatencao-a-mulheres-em-situacao-de-violencia-2013>. Acesso em: 3 jun. 2019.

DOMINGUES, F. Ministério diz que termo 'violência obstétrica' 
é 'inadequado' e deixará de ser usado pelo governo. Globo, 2019. Disponível em: <https://g1.globo.com/ciencia-e-

saude/noticia/2019/05/07/ministerio-diz-que-termoviolencia-obstetrica-tem-conotacao-inadequada-edeixara-de-ser-usado-pelo-governo.ghtml>. Acesso em: 09 nov. 2019.

G1. Ministério da Saúde reconhece legitimidade do uso do termo 'violência obstétrica'. Globo, 2019. Disponível em: <https://g1.globo.com/ciencia-esaude/noticia/2019/06/10/ministerio-da-saudereconhece-legitimidade-do-uso-do-termo-violenciaobstetrica.ghtml>. Acesso em: 09 nov. 2019.

GERHARDT, T.; SILVEIRA, D. Métodos de pesquisa. Porto Alegre: Editora da UFRGS, 2009. Disponível em: <http://www.ufrgs.br/cursopgdr/downloadsSerie/derad0 05.pdf>. Acesso em: 27 mar. 2019.

GIL, A. Como elaborar projetos de pesquisa. 6. Ed. São Paulo: Atlas, 2017.

LANGE, M. Outras dores além do parto: um estudo de caso com mulheres vítima da violência obstétrica. Santa Catarina, 2015. Disponível em: <https://riuni.unisul.br/handle/12345/3077>. Acesso em: 2 out. 2019.

LEAL, M. et al. Intervenções obstétricas durante o trabalho de parto e parto em mulheres brasileiras de risco habitual. Cad. Saúde Pública, Rio de Janeiro, v. 30, 2014. Disponível em: <http://www.scielo.br/pdf/csp/v30s1/0102-311Xcsp-30-s1-0017.pdf>. Acesso em: 5 mai. 2019.

MINISTÉRIO PÚBLICO DO ESTADO DO AMAPÁ. Em Defesa Delas: Promotor da saúde realiza palestra sobre violência obstétrica para defensores públicos do Amapá. MPAP, 2019. Disponível em <https://www.mpap.mp.br/noticias/gerais/em-defesadelas-promotor-da-saude-realiza-palestra-sobreviolencia-obstetrica-para-defensoras-e-defensorespublicos-do-amapa>. Acesso em: 28 nov. 2019.

MUNIZ, B.; BARBOSA, R. Problematizando o atendimento ao parto: cuidado ou violência? In: Memorias Convención Internacional de Salud Pública. Havana, 2012. Disponível em:

<http://www.convencionsalud2012.sld.cu/index.php/con vencionsalud/2012/paper/view/744>. Acesso em: 25 mai. 2019.

O GLOBO. MPF e OAB cobram que Ministério da Saúde volte atrás na decisão de abolir termo 'violência obstétrica', Globo, 2019. Disponível em: <https://oglobo.globo.com/sociedade/celina/mpf-oabcobram-que-ministerio-da-saude-volte-atras-na-decisaode-abolir-termo-violencia-obstetrica-23652278>. Acesso em: 09 nov. 2019.
PEREIRA, J.; et al. Violência obstétrica: ofensa à dignidade humana. Brazilian Journal of Surgery and Clinical Research - BJSCR, Belo Horizonte, v. 15, n. 1, p. 103-108, 2016. Disponível

em: <https://www.repositorio.ufop.br/handle/123456789/66 46>. Acesso em: 26 mai. 2019.

PORTELA, A; SILVA, E. A psicologia dialogando com a violência obstétrica e o direito da mulher: uma revisão bibliográfica. In: V Seminário internacional enlaçando sexualidades, 10, 2017, Recife, Anais... Recife: Faculdade Franssinetti do Recife, 2017. Disponível em: <https://www.editorarealize.com.br/revistas/enlacando/ trabalhos/TRABALHO_EV072_MD1_SA2_ID731_1806201 7030922.pdf >. Acesso em: 19 mai. 2019.

QUEIROZ, T. et al. Violência obstétrica e suas perspectivas na relação de gênero. Revista Científica Fagoc Saúde, v. 2. 2017. Disponível em: <http://revista.fagoc.br/index.php/saude/article/view/19 4/252>. Acesso em: 23 abr. 2019.

RADAR ODS. Casos de Violência obstétrica no Brasil foram evidenciados pela pesquisa da Rede Cegonha. Disponível em: <http://www.cee.fiocruz.br/radarods/?p=3210> Acesso em: 1 mai. 2019.

RIBEIRO, P. Significados da maternidade para mulheres que vivenciaram a violência obstétrica. 2017. Dissertação (Mestrado em Psicologia) - Instituto de Psicologia, Universidade Federal da Bahia, Salvador. Disponível em: $<$ https://repositorio.ufba.br/ri/handle/ri/24060>. Acesso em: 24 mar. 2019.

ROCHA, M.; GRISI, E. Violência obstétrica e suas influências na vida de mulheres que vivenciaram essa realidade. Id on Line Rev Mult Psic. v. 11, n. 38, 2017. Disponível em: < https://idonline.emnuvens.com.br/id/article/view/931/1 304>. Acesso em: 03 nov. 2019.

SANTOS, C.; IZUMINO, W. Violência contra as mulheres e violência de gênero: Notas sobre estudos feministas no Brasil. E.I.A.L. Estudios Interdisciplinarios de América Latina y El Caribe, Tel Aviv, 2005. Disponível em: <http://www.nevusp.org/downloads/down083.pdf>. Acesso em: 9 jun. 2019.

SILVA, F.; SILVA, M.; ARAUJO, F. Sentimentos causados pela violência obstétrica em mulheres de Município do Nordeste Brasileiro. Rev Pre Infec e Saude, Campina Grande, 3(4), p. 25-34, 2017. Disponível em: <http://www.ojs.ufpi.br/index.php/nupcis/article/view/6 924>. Acesso em: 01 nov. 2019.

SOUSA, V. A depressão no ciclo gravídico - puerperal de mulheres atendidas em um ambulatório de hospital geral. 2008. Dissertação (Mestrado em Enfermagem Psiquiátrica) - Escola de Enfermagem, Universidade de São Paulo, Ribeirão Preto. Disponível em: 
<http://www.teses.usp.br/teses/disponiveis/22/22131/t de-09122008-154716/pt-br.php>. Acesso em: 31 mai. 2019.

ZANARDO, G. et al. Violência obstétrica no Brasil: uma revisão narrativa. Psicologia \& Sociedade, Porto Alegre, v. 29. $2017 . \quad$ Disponível em: <https://www.redalyc.org/pdf/3093/309350113018.pdf> . Acesso em: 5 mai. 2019.

Submissão: 26/11/2019

Aprovado para publicação: 16/02/2020 